\title{
PENGEMBANGAN BUKU AJAR TRIGONOMETRI BERBASIS CONTEXTUAL TEACHING AND LEARNING UNTUK MAHASISWA PENDIDIKAN MATEMATIKA
}

\author{
Nurmala $R^{1}$ \\ ${ }^{1}$ Universitas Borneo Tarakan \\ 1nurmala.r17@gmail.com
}

\begin{abstract}
This research is a research and development which aims to produce a product in the form of a trigonometric textbook based on Contextual Teaching and Learning for Mathematics Education students. The development of teaching materials in this research refers to the Thiagarajan Model. This model consists of 4 stages of development,namely Define, Design, Develop, and Disseminates. The data analysis technique used is product feasibility test analysis and product practicality test analysis. The result of the research is that the product produced in the form of trigonometric textbooks based on Contextual Teaching and Learning is feasible and practical for use for mathematics education students. This is based on the data analysis of the experts, namely the material experts, respectively, obtained a percentage of $81 \%$ with proper criteria and $84 \%$ with very feasible criteria, each presentation expert obtained $92 \%$ with very feasible criteria and $89 \%$ with very feasible criteria. Based on the results of data analysis on student responses to large-scale trials, it was found that $79 \%$ stated that trigonometric textbook based on Contextual Teaching and Learning were very good and the remaining $21 \%$ stated that Contextual Teaching and Learning-based trigonometric textbooks were good.
\end{abstract}

Keywords: Development, textbook, Contextual Teaching and Learning

\begin{abstract}
Abstrak
Penelitian pengembangan ini bertujuan untuk menghasilkan produk yaitu buku teks trigonometri berbasis Contextual Teaching and Learning yang layak dan praktis untuk mahasiswa di jurusan Pendidikan Matematika. Pengembangan produk mengacu pada model Model Thiagarajan yaitu Define, Design, Develop, dan Disseminates. Analisis yang digunakan yaitu uji kelayakan dan analisis uji kepraktisan penggunaan produk. Berdasar pada analisis data para ahli materi diperoleh skor $81 \%$ berada pada kategori layak dan $84 \%$ berada pada kategori sangat layak. Pada ahli presentasi memperoleh 92\% dengan kategori sangat layak dan $89 \%$ dengan kategori layak. Adapun data respon siswa terhadap uji coba skala besar diketahui bahwa $79 \%$ menyatakan bahwa buku teks trigonometri berbasis Contextual Teaching and Learning berada pada kategori sangat baik dan $21 \%$ menyatakan buku teks trigonometri berbasis Contextual Teaching and Learning bagus.
\end{abstract}

Kata Kunci: Pengembangan, buku ajar, pembelajaran kontekstual

Cara Menulis Sitasi: R., Nurmala. (2021). Pengembangan Buku Ajar Trigonometri Berbasis Contextual Teaching and Learning untuk Mahasiswa Pendidikan Matematika. Mathematic Education and Aplication Journal, volume 3 no.1, halaman 10-19

Trigonometri merupakan mata kuliah wajib jurusan Pendidikan Matematika di Universitas Borneo Tarakan (UBT). Trigonometri merupakan materi yang penting bagi mahasiswa jurusan Pendidikan Matematika UBT karena materi trigonometri merupakan pendukung mata kuliah yang lain, diantaranya adalah mata kuliah aljabar, kalkulus, dan mata kuliah persamaan differensial. Dalam pembelajaran trigonometri, materi yang diberikan kepada mahasiswa terkait dengan materi ukuran sudut, rumus-rumus perbandingan trigonometri, jumlah dan selisih sudut trigonometri, trigonometri untuk sudut-sudut berelasi, grafik fungsi trigonometri, aturan dalam segitiga, dan persamaan trigonometri. 
Berdasarkan pengalaman mengajar dosen yang mengampu trigonometri di Pendidikan Matematika UBT, diperoleh informasi bahwa belum tersedianya bahan ajar yang memadai untuk diaplikasikan dalam proses belajar mengajar. Sebagian besar menggunakan referensi dari internet dan beberapa buku di perpustakaan yang sangat terbatas. Hal ini berakibat mahasiswa kurang optimal dalam mengikuti perkuliahan. Maka itu pentingnya inovasi dalam perkuliahan agar proses belajar mengjar dapat berjalan secara maksimal di kelas. Salah satu upaya yang dapat ditempuh dalam mengoptimalkan proses pembelajaran adalah penyusunan buku ajar trigonometri berbasis kontekstual yang dapat digunakan oleh mahasiswa pendidikan matematika UBT. Dengan adanya buku ajar yang disusun berdasarkan RPS, maka mahasiswa lebih mudah memahami materi yang disajikan dan dapat menyiapkan pembelajaran sebelumnya sehingga lebih siap mengikuti pembelajaran. Hal tersebut juga membuat mahasiswa tidak bergantung kepada dosen sehingga pembelajaran lebih optimal dan efektif.

Pembelajaran yang efektif ditandai dengan adanya proses belajar dalam siswa, wawasan berpikir yang beragam sehingga siswa dapat mempelajari berbagai konsep dan mampu mengkaitkannya dengan kehidupan nyata (Iskandar \& Andriyani, 2019). Dalam proses pembelajaran, terdapat banyak pendekatan pembelajaran yang memperhatikan konteks pembelajar dengan mengaitkan materi dengan kehidupan nyata, salah satunya adalah pendekatan kontekstual. Pembelajaran kontekstual merupakan suatu proses pembelajaran yang mengaitkan materi pokok bahasan pembelajaran dengan konteks dunia nyata yang dihadapi oleh peserta didik dalam kehidupan sehari-hari baik itu dalam lingkungan keluarga, masyarakat, alam sekitar, ataupun dalam dunia pekerjaan sehingga peserta didik memiliki kemampuan dalam mengaitkan antara pengetahuan yang dimilikinya dengan penerapannya dalam kehidupan sehari-hari yang melibatkan komponen utama pembelajaran yakni : constructivism, questioning, inquiry, learning community, modeling, reflection, dan authentic assessment (Sinaga \& Situmorang, 2015). Suatu proses pembelajaran dapat dikatakan menggunakan pendekatan kontekstual jika materi pokok bahasan pembelajaran tidak hanya bersifat tekstual, namun juga dikaitkan dengan penerapannya dalam kehidupan sehari-hari.

Keberadaan sumber belajar mempunyai tujuan utama yaitu diantaranya adalah memberikan informasi-informasi yang dibutuhkan dalam menyusun bahan ajar sebelum melaksanakan proses pembelajaran, dapat dipergunakan oleh dosen atau tenaga pengajar dalam menyusun bahan ajar, dan memudahkan bagi peserta didik untuk mempelajari dan memahami suatu kompetensi tertentu terkait materi yang dipelajari. Sehingga sebagai seorang pendidik kita dituntut untuk dapat secara aktif dan kreatif dalam merancang suatu bahan ajar yang dapat digunakan dan dimanfaatkan sebagai sumber belajar secara langsung. (Perwitasari, 2018).

Buku ajar sebagai salah satu sumber belajar, memiliki ciri khas tersendiri dibandingkan dengan buku-buku lainnya. Hal tersebut dapat dilihat dari isinya, yaitu buku ajar berisi tentang uraian materi ajar yang akan disajikan dalam proses pembelajaran untuk bidang tertentu dan pada kurun waktu tertentu pula. Selain itu segi penyajiannya, buku ajar merupakan sumber belajar yang memperhatikan faktor (1) tujuan dari pembelajaran, (2) kurikulum pendidikan, (3) kondisi dan 
fasilitas infrastruktur, (4) tingkat perkembangan sasaran, (5) kondisi pengguna. Sedangkan untuk fungsinya yaitu selain memiliki fungsi umum sebagai suatu buku, buku ajar sebagai sumber belajar mempunyai fungsi sebagai berikut yaitu (1) sebagai sarana dalam mengembangkan materi bahan belajar dan program dalam kurikulum pendidikan, (2) sebagai sarana membantu menyelesaikan tugas akademik guru, (3) sebagai sarana pemenuhan ketercapaian tujuan pembelajaran dan (4) sebagai sarana pendorong efisiensi dan efektifitas kegiatan proses pembelajaran (Prastowo, 2011).

Berdasarkan uraian yang dikemukakan tersebut, tujuan penelitian ini adalah untuk mengetahui kelayakan dan kepraktisan buku ajar trigonometri berbasis contextual teaching and learning untuk mahasiswa pendidikan matematika.

\section{METODE}

Metode penelitian dan pengembangan mengacu pada model Model Thiagarajan yaitu tahap pendefinisian (define), prancangan (design), pengembngan (develop) dan diseminasi (disseminate). Adapun tahap-tahap pada model Model Thiagarajan sebagai berikut (Nurmala R \& Susanti, 2019):

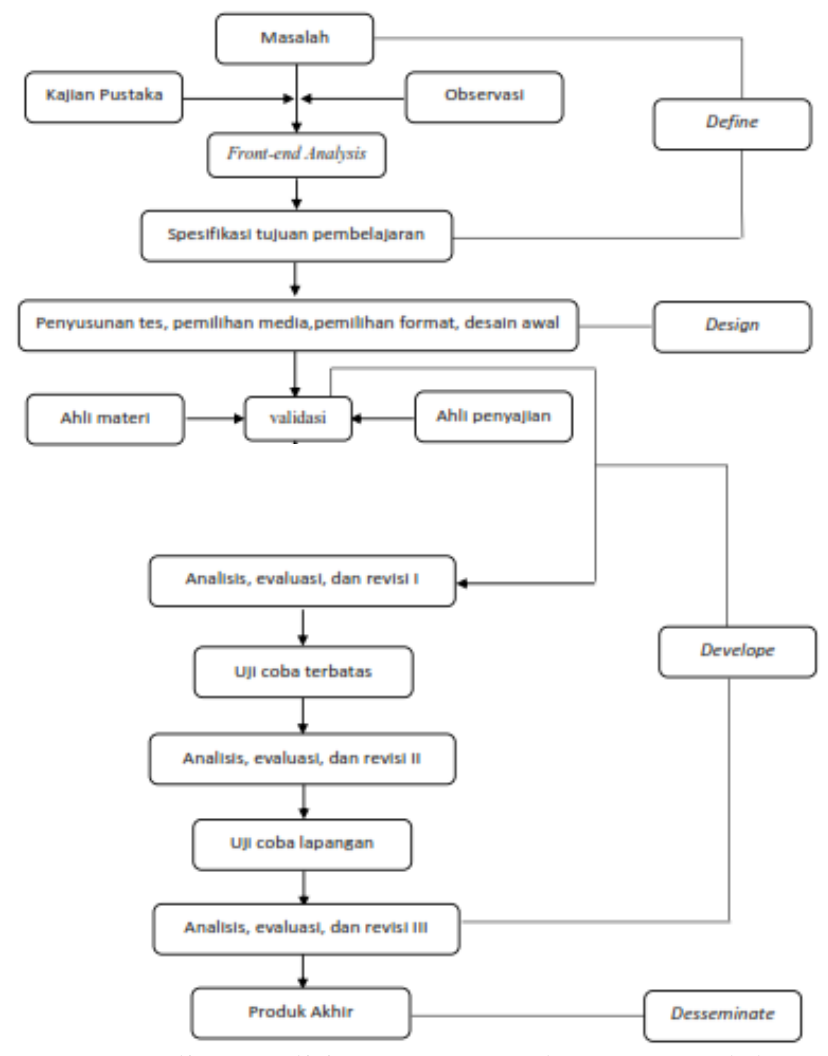

Gambar 1. Bagan Alir Penelitian \& Pengembangan Model 4-D yang diadaptasi dari Thiagarajan (Nurmala R \& Susanti, 2019)

Adapun teknik dan instrumen penelitian dalam pengumpulan data sebagai berikut :

\section{Dokumentasi}

Dokumen yang digunakan adalah dokumen yang diperoleh dari hasil pengembangan buku ajar trigonometri berbasis contextual teaching and learning. Selain itu, peneliti juga melaksanakan studi refrensi baik dari buku cetak maupun refrensi dari internet. Semua data dokumen yang dihasilkan adalah data yang menunjang dalam menghasilkan produk buku ajar trigonometri. 


\section{Observasi}

Observasi dilakukan sebelum membuat produk buku ajar. Observasi bertujuan untuk mendapatkan informasi mengenai permasalahan dalam perkuliahan mata kuliah trigonometri serta informasi ketersedian bahan ajar trigonometri yang digunakan dalam kelas.

3. Lembar penilaian

Lembar penilaian yang dimaksud adlah suatu media yng digunakan untuk menilai produk yang telah dikembangkan dan diserahkan kepada para ahli untuk mengetahui kelayakan produk. Lembar penilaian ahli terkait dengan kelayakan konten isi materi dan kelaykan penyajian bahan ajar yang telah dibuat.

4. Lembar angket

Angket merupakan salah satu data pendukung untuk mengujikepraktisan produk yang disebarkan dengan tujuan untuk mengetahui pendapat pengguna mengenai produk yang dikembangkan.

Data yang diperoleh dalam penelitian, kemudian dianalisis secara data kuantitatif untuk menjelaskan kelayakan dan kepraktisan produk yang dikembangkan. Adapun data validasi oleh validator untuk menjelaskan kelayakan produk yang telah dibuat, dan data hasil penyebaran lembar angket menjelaskan kepraktisan produk.

Data penilaian ahli dan tanggapan mahasiswa diukur dengan rumus sebagai berikut (Arikunto, 2012):

$$
K=\frac{\sum n i}{N} \times 100 \%
$$

$$
\begin{aligned}
& \text { Keterangan: } \\
& \mathrm{K}=\text { prsentase skor yang telah diperoleh } \\
& \sum \mathrm{ni}=\text { jumlh skor yang telah diperoleh } \\
& \mathrm{Nk}=\text { jumlah skor maksimal }
\end{aligned}
$$

Perhitungan yang diperoleh dimasukkan ke dalam tabel persentase menyesuaikan dengan ktegori penerapan . Cara menentukan kategori penerapan adalah dengan menentukan persentase tertinggi dan terendah dengan rumus (Nurmala R \& Izzatin, 2018).

$$
\begin{aligned}
& \text { Persentase tertinggi }=\frac{\sum \text { item } x \sum \text { responden } x \text { Skor tertinggi }}{\sum \text { item } x \sum \text { responden } x \text { Skor terting } i} \times 100 \% \\
& \text { Persentase tertinggi }=\frac{\sum \text { item } x \sum \text { responden } x \text { Skor terendah }}{\sum \text { item } x \sum \text { responden } x \text { Skor terting } i} \times 100 \% \\
& \text { Interval Kelas }=\frac{\% \text { tertinggi }-\% \text { terendah }}{\text { jumlah kelas }}=\frac{100-25}{4}=18,75
\end{aligned}
$$


Berdasarkan rumus di atas, kategori yang diterapkan adalah:

Tabel 1. Kategori Kelayakan Buku

\begin{tabular}{|l|c|}
\hline \multicolumn{1}{|c|}{ Skor $(\%)$} & Kategori \\
\hline $82<$ skor $\leq 100$ & Sangat layak \\
\hline $63<$ skor $\leq 82$ & Layak \\
\hline $44<$ skor $\leq 63$ & Cukup layak \\
\hline $25<$ skor $\leq 44$ & Tidak layak \\
\hline
\end{tabular}

\section{HASIL DAN PEMBAHASAN}

Produk yang dihasilkan dalam penelitian ini adalah buku ajar trigonometri berbasis contextual teaching and learning untuk mahasiswa pendidikan matematika dengan menggunakan desain penelitian dan pengembangan model Thiagarajan yaitu tahap pendefinisian (define), perancangan (design), pengembangan (develop) dan diseminasi (disseminate).

Pada tahapan pendefenisian, diperoleh bahwa: (1) melaksanakan observasi dan wawancara dengan mahasiswa yang memprogramkan trigonometri sebagai bentuk proses prapenelitian. (2) Mahasiswa yang merupakan tingkat awal dapat dikelompokkan dalam tingkat operasional formal dimana mahasiswa pada tingkat ini memiliki pemikiran jauh, mereka dapat memahami yang abstrak, mempunyai kemampuan dalam membuat hipotesis, membuat analogi, dan dapat mengevaluasi diri. Dalam hal ini, mahasiswa Pendidikan Matematika UBT mempunyai ciri-ciri operasional formal meski tidak secara menyeluruh. Mereka lebih cenderung menyukai perkuliahan yang bersifat teknologi dan visualisasi dibandingkan proses perkuliahan konvensional seperti ceramah dan teks book. (3) Analisis tugas yaitu rincian isi konten materi pengajaran yang akan disampaikan di kelas dan berkesesuaian dengn RPS yang dibuat oleh dosen pengampu. (4) Analisis konsep yaitu identifikasi konsep-konsep yang paling utama yang akan diajarkan serta merumuskan secara sistematis dan menghubungkan suatu konsep dengan konsep lainnya yang relevan. (5) Analisis tujuan pembelajaran dilaksanakan untuk melihat tujuan pembelajaran yang harus dicapai dalam proses perkuliahan.

Pada tahap perancangan buku ajar diawali dengan menyiapkan buku refrensi yang berkaitan dengan materi trigonometri. Masalah yang disajikan dalam buku ajar ini adalah permasalahan yang kaitannya dengan kehidupan sehari-hari. Berikut gambaran buku ajar trignometri berbasis contextual teaching and learning:

1. Media penyimpanan : Flash Disk dan Kertas 70 gr

2. Ketebalan : 100 halamn

3. Format : Portable Document Format 


\section{Jenis Huruf : Book Antiqua, Trebuchet MS \\ 5. Materi \\ : Trigonometri}

Adapun kerangka buku ajar dan sistematika penyusunan materi sebagai berikut:

1. Sampul buku

2. Kata pengantar

3. Daftar isi

4. Sejarah trigonometri

5. Isi materi trigonometri

6. Latihan soal

7. Daftar Pustaka

Selanjutnya pada tahap pengembangan telah dibuat draft awal buku ajar trigonometri trigonometri berbasis contextual learning and teaching. Draft awal produk kemudian diserahkan kepada validator melalui tahapan validasi yaitu validasi penyajian/tampilan dan validasi ahli materi. Hasil validasi pada produk terdapat beberapa revisi dengan perbaikan-perbaikan yang disarankan oleh validator. Berdasarkan analisis data dan indikator ketercapaiannya, maka produk yang dikembangkan yaitu buku ajar trigonometri berbasis contextual teaching and learning dinyatakan layak digunakan untuk mahasiswa pendidikan matematika karena diperoleh hasil pada pengkategorian sangat layak pada validasi penyajian dan berada pada kategori layak untuk validasi ahli materi. Dalam tahapan ini juga dilaksanakan uji coba dalam bentuk skala kecil dan uji coba dalam skala besar terhadap mahasiswa Pendidikan Matematika untuk melihat kepraktisan dalam penggunaan buku ajar trigonometri berbasis contextual teaching and learning.

Validasi ahli dalam penyajian diberikan kepada pakar ahli di bidangnya dengan tujuan untuk melihat produk apakah layak digunakan atau tidak layak.

Tabel 2. Hasil analisis validasi ahli penyajian

\begin{tabular}{|c|l|c|c|}
\hline \multirow{2}{*}{ No } & \multicolumn{1}{|c|}{ Indikator } & \multicolumn{2}{|c|}{ Validator } \\
\cline { 3 - 4 } & & I & II \\
\hline 1 & Organisasi penyajian Buku Ajar & 4 & 4 \\
\hline 2 & $\begin{array}{l}\text { Organisasi penyajian per pokok bahasa/sub pokok bahasan yang } \\
\text { disajikan }\end{array}$ & 4 & 3 \\
\hline 3 & $\begin{array}{l}\text { Penyajian mempertimbangkan kebermaknaan dan } \\
\text { kebermanfaatan buku ajar }\end{array}$ & 4 & 3 \\
\hline 4 & Buku ajar melibatkan mahasiswa secara aktif & 3 & 3 \\
\hline 5 & Tampilan layout buku ajar & 3 & 4 \\
\hline 6 & Penyampaian informasi dalam buku ajar & 4 & 4 \\
\hline 7 & Anatomi buku ajar TOTAL & 4 & 4 \\
\hline \multicolumn{2}{|c|}{26} & 25 \\
\hline
\end{tabular}


Berdasarkan analisis skor dari masing-masing validator dieroleh skor 26 dengan persentase 92\% (sangat layak) dari validator I dan skor total 25 dari validator II dengan persentase 89\% (sangat layak). Sehingga dapat disimpulkan bahwa produk buku ajar trigonometri berbasis contextual teaching and learning layak digunakan untuk mahasiswa pendidikan matematika karena berada dalam kategori sangat layak.

Terdapat beberapa saran dari validator ahli penyajian diantaranya adalah terdapat beberapa kata salah dalam pengetikan/penulisan sehingga perlu diperbaiki agar pengguna produk tidak bingung ketika menggnakan produk tersebut. Selain itu, ada contoh soal yang sama dalam satu materi pembelajaran sehingga disarankan untuk menghilangkan soal yang sama. Selanjutnya, saran yang lainnya, yaitu menyempurnakan tampilan produk yang masih standar sederhana agar pengguna dapat lebih tertarik lagi dalam menggunakan produk buku ajar dalam perkuliahan.

Sebelum rexisi

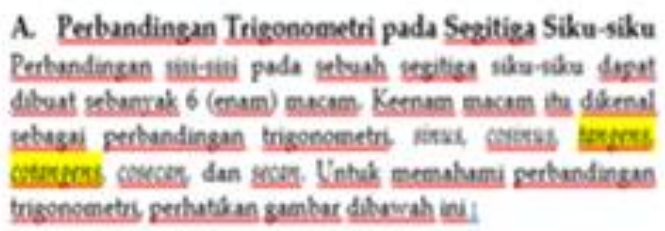

jam sehingea dipereleh hasil seperti yang dituniukan gambar B2. Sudet antara jaram jam dengan garis OP mercipakan lgrek

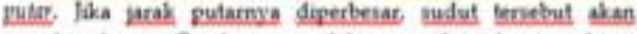
semakin beses. Gerak jonom dalam sambar di atas dapat dilukikan oleh gerak das jasian lingkaran segerti diperilhatkan pade sambar 3 .

\section{setelah rexigi}

Gambar 2. Revisi berdasarkan masukan validator

a. Validasi ahli materi

Validasi ahli materi dilakukan untuk mengetahui materi yang telah disajikan/disampaikan dalam produk sudah berkesesuaian dengan indikator yang akan diukur, apakah layak dan tidak layaknya produk yang dihasilkan.

Tabel 3. Hasil Analisis Validasi Ahli Materi

\begin{tabular}{|c|l|c|c|}
\hline \multirow{2}{*}{ No } & \multicolumn{1}{|c|}{ Indikator } & \multicolumn{2}{|c|}{ Validator } \\
\cline { 2 - 4 } & $\mathrm{I}$ & $\mathrm{II}$ \\
\hline 1 & $\begin{array}{l}\text { Buku Ajar disajikan secara sistematis dan berbasis contextual teaching } \\
\text { and learning }\end{array}$ & 4 & 4 \\
\hline 2 & Buku ajar merupakan bahasan yang esensial & 3 & 3 \\
\hline 3 & Masalah yang disajikan sesuai tingkat kognisi pengguna & 3 & 4 \\
\hline 4 & $\begin{array}{l}\text { Setiap pokok bahasan/sub pokok bahasan yang disajikan mempunyai } \\
\text { tujuan yang jelas }\end{array}$ & 3 & 3 \\
\hline 5 & $\begin{array}{l}\text { Penyajian Buku ajar berbasis contextual teaching and learning } \\
\text { dilengkapi dengan gambar atau ilustrasi }\end{array}$ & 3 & 3 \\
\hline
\end{tabular}




\begin{tabular}{|c|l|c|c|}
\hline 6 & $\begin{array}{l}\text { Produk yang dikembangkan dapat mengembangkan keterampilan dan } \\
\text { kemampuan berfikir }\end{array}$ & 4 & 3 \\
\hline 7 & $\begin{array}{l}\text { Penyajian Lembar Kerja Mahasiswa dapat melatih keaktifan dan } \\
\text { kreatifitas mahasiswa }\end{array}$ & 3 & 3 \\
\hline 8 & $\begin{array}{l}\text { Materi buku ajar trigonometri berbasis contextual teaching and learning } \\
\text { mudah difahami oleh mahasiswa }\end{array}$ & 3 & 4 \\
\hline \multicolumn{1}{|c|}{ TOTAL } & 26 & 27 \\
\hline
\end{tabular}

Berdasarkan tabel di atas diperoleh bahwa, skor total 26 dari Validator I dengan persentase $81 \%$ (layak) dan skor 27 validator II dengan persentase 84\% (sangat layak). Maka dari indikator pencapaiannya, produk layak digunakan karena berada pada kategori layak dan sangat layak.

\section{b. Hasil Uji Coba dalam bentuk Skala Kecil dan Revisi}

Uji coba dalam bentuk skala kecil dilakukan setelah revisi kecil yang disarankan oleh para ahli validator materi dan validator penyajian dengan peserta 10 orang. Instrumen yang digunakan adalah buku ajar Trigonometri berbasis Contextual Teaching and Learning dan lembar angket tanggapan pengguna yaitu mahasiswa. Hasil analisis angket tanggapan pengguna mahasiswa terhadap buku ajar Trigonometri berbasis Contextual Teaching and Learning disajikan sebagai berikut:

Tabel 4. Hasil Uji Coba Skala Kecil

\begin{tabular}{|c|c|c|c|}
\hline No & Pernyataan & Ya & Tidak \\
\hline 1 & $\begin{array}{l}\text { Kalimat dalam buku ajar sesuai dengan Pedoman Umum } \\
\text { Ejaan Bahasa Indonesia (PEUBI) }\end{array}$ & $90 \%$ & $10 \%$ \\
\hline 2 & Penggunaan symbol-simbol dalam buku yang tepat & $70 \%$ & $30 \%$ \\
\hline 3 & Tulisan yang disajikan dalam produk buku jelas & $90 \%$ & $10 \%$ \\
\hline 4 & Bahasa buku yang digunakan bersifat komunikatif & $90 \%$ & $10 \%$ \\
\hline 5 & $\begin{array}{l}\text { Bahasa yang digunakan tidak bersifat ambigu (bermakna } \\
\text { ganda) }\end{array}$ & $100 \%$ & $00 \%$ \\
\hline 6 & Gambar-gambar yang disajikan dalam buku jelas & $80 \%$ & $20 \%$ \\
\hline 7 & $\begin{array}{l}\text { Ukuran font yang digunakan tidak terlalu kecil dan tidak } \\
\text { terlalu besar sehingga mudah dibaca }\end{array}$ & $100 \%$ & $0 \%$ \\
\hline
\end{tabular}

Hasil uji coba dalam bentuk skala kecil memperlihatkan bahwa terdapat beberapa poin dalam buku ajar trigonometri berbasis contextual teaching and learning yang memerlukan perbaikan. Beberapa tanggapan pengguna mahasiswa dan perbaikan yang telah dilakukan dapat dilihat pada tabel berikut:

Tabel 5. Revisi Uji Coba dalam bentuk Skala Kecil

\begin{tabular}{|c|l|l|}
\hline No & \multicolumn{1}{|c|}{ Tanggapan Mahasiswa } & \multicolumn{1}{c|}{ Perbaikan } \\
\hline 1 & $\begin{array}{l}10 \% \text { menyatakan kalimat yang terdapat dalam bahan } \\
\text { ajar kurang sesuai dengan PEUBI }\end{array}$ & $\begin{array}{l}\text { Perbaikan kalimat yang kurang } \\
\text { sesuai dengan PEUBI }\end{array}$ \\
\hline 2 & $\begin{array}{l}\text { Sebanyak 30\% menyatakan penggunaan symbol- } \\
\text { simbol dalam produk kurang jelas dalam } \\
\text { penulisannya }\end{array}$ & $\begin{array}{l}\text { Perbaikan symbol dengan } \\
\text { bemarsesuai dengan bagian yang } \\
\text { dimaksud. }\end{array}$ \\
\hline
\end{tabular}




\begin{tabular}{|c|l|l|}
\hline 3 & $\begin{array}{l}10 \% \text { menyatakan tulisan dalam buku ajar kurang } \\
\text { jelas }\end{array}$ & $\begin{array}{l}\text { Memperbaiki beberapa } \\
\text { penulisan dalam buku ajar } \\
\text { sehingga dapat difahami maksud } \\
\text { tulisannya }\end{array}$ \\
\hline 4 & $\begin{array}{l}\text { Sebanyak 10\% menyatakan bhasa yang digunakan } \\
\text { dalam buku tidak bersifat komunikatif }\end{array}$ & $\begin{array}{l}\text { Melakukan perbaikan terkait } \\
\text { bahasa yang bersifat tidak } \\
\text { komunikatif }\end{array}$ \\
\hline 5 & $\begin{array}{l}\text { Sebanyak 20\% pengguna menyatakan gambar- } \\
\text { gambar yang disajikan kurang jelas }\end{array}$ & $\begin{array}{l}\text { Mengganti gambar yang } \\
\text { dimaksud dengan gambar } \\
\text { yangjelas }\end{array}$ \\
\hline
\end{tabular}

c. Hasil Uji Coba dalam bentuk Skala Luas dan Revisi

Uji coba dalam bentuk skala luas diberikan kepada pengguna mahasiswa Pendidikan Matematika UBT yang program mata kuliah trigonometri semester ganjil 2020/2021. Uji coba dalam skala luas dilakukan dalam rangka mendapatkan data tanggapan pengguna mahasiswa terhadap penggunaan buku ajar trigonometri berbasis contextual teaching and learning dalam perkuliahan dan tanggapan pengguna mahasiswa setelah menggunakan produk yang dikembangkan.

Tabel 6. Data tanggapan pengguna mahasiswa terhadap buku ajar trigonometri berbasis contextual teaching and learning pada uji coba skala luas

\begin{tabular}{|l|c|}
\hline \multicolumn{1}{|c|}{ Kriteria } & Jumlah Siswa \\
\hline Sangat Baik & 41 \\
\hline Baik & 11 \\
\hline Kurang Baik & 0 \\
\hline Tidak Baik & 0 \\
\hline
\end{tabular}

Hasil analisis tanggapan pengguna mahasiswa pada uji coba dalam bentuk skala besar diperoleh bahwa $79 \%$ yang menyatakan bahwa buku ajar trigonometri berbasis contextual teaching and learning untuk mahasiswa pendidikan matematika berada pada sangat baik. Dan $21 \%$ mahasiswa menyatakan bahwa produk buku ajar trigonometri berbasis contextual teaching and learning untuk mahasiswa pendidikan matematika berada pada baik. Sehingga dapat disimpulkan bahwa buku ajar trigonometri berbasis contextual teaching and learning layak dan praktis digunakan untuk mahasiswa pendidikan matematika.

Pada tahap akhir dari penelitian ini adalah tahap desiminasi yang bersifat terbatas, yaitu dengan menyebarluaskan dan mempromosikan produk final secara terbatas kepada mahasiswa dan dosen pendidikan matematika UBT.

\section{KESIMPULAN}

Berdasarkan hasil dan pembahasan, maka dapat disimpulkan bahwa produk yang dikembangkan yaitu buku teks trigonometri berbasis contextual learning and teaching layak dan praktis untuk digunakan dalam proses perkuliahan Trigonometri. Analisis data didapatkan $81 \%$ 
dengan kategori layak dan 84\% dengan kategori sangat layak untuk ahli materi, sedangkan ahli penyajian diperoleh 92\% dengan kategori sangat layak dan $89 \%$ dengan kategori sangat layak. Adapun analisis data tanggapan pengguna mahasiswa pada uji coba dalam bentuk skala besar diperoleh bahwa sebanyak 79\% yang menyatakan bahwa buku ajar trigonometri berbasis Contextual Teaching and Learning sangat baik dan $21 \%$ menyatakan bahwa buku ajar trigonometri berbasis Contextual Teaching and Learning baik.

\section{DAFTAR PUSTAKA}

Arikunto. (2012). Dasar-dasar Evaluasi Pendidikan. In Jakarta : Bumi Aksara. Bumi Aksara.

Iskandar, F., \& Andriyani, R. (2019). Pengembangan Bahan Ajar Trigonometri untuk Meningkatkan Kemampuan Berpikir Kritis Matematis Mahasiswa. Prosiding PRISMA, 759-763.

Nurmala R, \& Izzatin, M. (2018). Pengembangan Bahan Ajar Pembelajaran PDM Berbasis Buku Teks untuk Menumbuhkan Kemandirian Belajar Mahasiswa Pendidikan Matematika. Borneo Saintek, 1(3), 40-50. https://doi.org/https://doi.org/10.35334/borneo_saintek.v1i3.933

Nurmala R, \& Susanti, D. (2019). Pengembangan Bahan Ajar Trigonometri berbasis Literasi Matematika. Borneo Saintek, 2(1), 37-45.

http://jurnal.borneo.ac.id/index.php/borneo_saintek/issue/view/57/showToc

Perwitasari, S. (2018). Pengembangan Bahan Ajar Tematik Berbasis Kontekstual. Jurnal Pendidikan :Teori, Penelitian Dan Pengembangan, 3(3), 278-285.

Prastowo, A. (2011). Panduan Kreatif Membuat Bahan Ajar Inovatif. In Yogyakarta: Diva Press.

Sinaga, M., \& Situmorang, M. (2015). Pengembangan Bahan Ajar Berbasis Kontekstual untuk Meningkatkan Hasil Belajar Mahasiswa Pada Pengajaran Reaksi Redoks. Prosiding SEMIRATA, $549-558$. 